\title{
PENINGKATAN KUALITAS SUMBER DAYA MANUSIA MENUJU RUMAH SAKIT SYARI'AH MELALUI APLIKASI "SIAPA"
}

\author{
Dasya Arief Firmansah ${ }^{1}$, Ramdhan Saepul Rohman ${ }^{2}$, Erni Ermawati ${ }^{3}$ \\ 1 Universitas Bina Sarana Informatika \\ e-mail: dasya.daf@bsi.ac.id \\ 2Universitas Bina Sarana Informatika \\ e-mail:ramdhan.rpe@bsi.ac.id \\ 3 Universitas Bina Sarana Informatika \\ e-mail:erni.ert@bsi.ac.id
}

\begin{abstract}
Abstrak
Semakin baik kualitas sumber daya manusia semakin baik pula dampaknya terhadap pelayanan kesehatan yang ada. Hal ini tentunya menjadi perhatian yang sangat serius bagi pihak rumah sakit dalam meningkatkan kualitas sumber daya manusianya. Telah dilakukan banyak cara guna merealisasikan maksud tersebut, sehingga kualitas sumber daya manusia semakin unggul dan dapat beradaptasi dengan baik di era persaingan teknologi revolusi industri 4.0. Mengingat rumah sakit islam assyifa merupakan sakit yang lebih mengedepankan nilai-nilai islam Salah satu kegiatan yang rutin dilakukan adalah pengajian mingguan Kegiatan pengajian ini dilakukan sebanyak empat kali dalam satu bulan dan setiap karyawan diwajibkan untuk mengikuti minimal sebanyak 120 menit. Mengingat kesibukan setiap karyawan sangat beragam maka tidak semua karyawan bisa mengikuti pengajian di setiap minggunya bahkan tidak sedikit karyawan yang mengikuti pengajian kurang dari waktu yang telah ditentukan. Proses pencatatan yang masih manual juga menjadi salah satu kendala perhitungan akumulasi jumlah jam masuk dan keluar, sehingga tidak jarang terjadi kesaahan input maupun perhitungan. Untuk meminimalisir segala jenis kesalahan yang sering ditemui dirancanglah sebuah aplikasi yang dapat mengoptimallkan kegiatan tersebut. Sistem tersebut diberi nama sistem aplikasi SIAPA (Sistem Informasi Absen Pengajian).
\end{abstract}

Kata Kunci: Sumber daya manusia, Aplikasi, Absensi, Pengajian, Rumah Sakit.

\begin{abstract}
The better the quality of human resources, the better the impact on existing health services. This is certainly a very serious concern for the hospital in improving the quality of its human resources. Many ways have been done to realize this intention, so that the quality of human resources is superior and can adapt well in the era of industrial revolution technology competition 4.0. Considering the Islamic hospital Assyifa is a sickness that emphasizes Islamic values. One of the routine activities is weekly recitation. This recitation activity is carried out four times a month and each employee is required to attend at least 120 minutes. Considering the busyness of each employee is very diverse, not all employees can attend the recitation on a weekly basis, not even a few employees who attend the recitation less than the specified time. The manual recording process is also one of the obstacles in calculating the accumulation of hours of entry and exit, so that input and calculation errors are not uncommon. To minimize all types of errors that are often encountered an application is designed that can optimize these activities. The system was given the name of the application system SIAPA (Absence Study Information System).
\end{abstract}

Keywords: Human resources, Application, Attendance, Recitation, Hospital. 


\section{Pendahuluan}

Rumah sakit merupakan organisasi yang menjual jasa pelayanan kesehatan, sehingga industri pelayanan dituntut untuk dapat memenuhi keinginan dan harapan pasien (Kurniawan \& Oki Rosanto, 2018).

Rumah sakit Islam Assyifa sukabumi atau yang akrab disebut RSI Assyifa Sukabumi merupakan salah satu rumah sakit syariah di kota sukabumi.

Rumah sakit syariah sendiri merupakan rumah sakit yang mana seluruh aktifitasnya berdasarkan pada maqashid syariah atau tujuan Islam (Basarah, 2017). Pada pelaksanaannya rumah sakit syariah berdasarkan pada fatwa yang telah ditetapkan oleh Dewan Syariah Nasional (DSN) Majelis Ulama Indonesia (MUI) No. 107/DSN-MUI/X/2016, tentang pedoman penyelenggaraan rumah sakit berdasarkan prinsip syariah, yang di dalamnya ada beberapa ketentuan yang wajib dilakukan bagi rumah sakit yang menerapkan prinsipprinsip syariah.

Sumber daya manusia merupakan bagian penting yang perlu mendapat perhatian. Sumber daya manusia yaitu tenaga kerja atau karyawan, memegang peranan yang sangat penting bagi peningkatan kinerja atau kemajuan suatu perusahaan (Dipang, 2013)

Sumber daya manusia juga merupakan asset terpenting dalam suatu perusahaan yang ikut serta dalam menunjang tingkat keberhasilan suatu bisnis. Perusahaan tidak dapat berjalan dengan baik tanpa adanya peran sumber daya manusia (Rahardja et al., 2015).

Pelayanan rumah sakit yang optimal tentunya tidak terlepas dari kualitas sumber daya manusia yang tersedia. Semakin baik kualitas sumber daya manusia semakin baik pula dampaknya pada pelayanan yang ada. Hal ini tentunya menjadi perhatian yang sangat serius bagi pihak rumah sakit dalam meningkatkan kualitas sumber daya manusianya. RSI Assyifa Sukabumi telah melakukan banyak cara guna merealisasikan maksud tersebut, sehingga kualitas sumber daya manusia semakin unggul dan tentunya dapat beradaptasi dengan baik di era persaingan teknologi saat ini.

Teknologi merupakan perkembangan dari kebudayaan yang maju dengan pesat (Rahman, 2019). Teknologi informasi adalah suatu perangkat yang digunakan seseorang untuk mangolah data,mendapatkan informasi dan sangat berpengaruh terhadap lingkungan di masyarakat serta memberikan dampak yang negatif dan positif pula tergantung bagaimana seseorang menggunakannya (Zulfah, 2018).

Mengingat rumah sakit islam assyifa merupakan rumah sakit yang lebih mengedepankan nilai-nilai islam maka disamping dibekali dengan keilmuan medis, umum maupun keilmuan lainnya RSI Assyifa juga membekali karyawannya dengan keilmuan islam sehingga pengetahuan karyawan menjadi lebih beragam dan tidak terlepas dari nilai-nilai islami. Salah satu kegiatan yang rutin dilakukan adalah pengajian mingguan.

Pengajian Islam adalah satu disiplin ilmu yang luas yang berkaitan secara langsung dengan agama Islam dan perlaksanaannya, merangkumi bidang Usuluddin dan bidang Syariah dari tauhidnya sehinggalah kepada fikahnya (European Environment Agency (EEA), 2019).

Kegiatan pengajian ini dilakukan sebanyak empat kali dalam satu bulan dan setiap karyawan diwajibkan untuk mengikuti minimal sebanyak 120 menit. Mengingat kesibukan setiap karyawan sangat beragam maka tidak semua karyawan bisa mengikuti pengajian di setiap minggunya bahkan tidak sedikit karyawan yang mengikuti pengajian kurang dari waktu yang telah ditentukan. Proses pencatatan yang masih manual juga menjadi salah satu kendala perhitungan akumulasi jumlah jam masuk dan keluar, sehingga tidak jarang terjadi kesalahan input maupun perhitungan. Untuk meminimalisir segala jenis kesalahan yang sering ditemui dirancanglah sebuah aplikasi yang dapat mengoptimallkan kegiatan tersebut. Sistem tersebut diberi nama dengan sistem aplikasi SIAPA (Sistem Informasi Absen Pengajian)

\section{Metode Penelitian}

$\begin{array}{cc}\text { Menurut } & \begin{array}{c}\text { Sommerville } \\ \text { Metode } \\ \text { (Sasmito, 2017) }\end{array} \text { waterfall }\end{array}$ merupakan model pengembangan sistem informasi yang sistematik dan sekuensial, Metode Waterfall memiliki tahapan-tahapan sebagai berikut : 
a. Requirements analysis and definition Layanan sistem, kendala, dan tujuan ditetapkan oleh hasil konsultasi dengan pengguna yang kemudian didefinisikan secara rinci dan berfungsi sebagai spesifikasi sistem.

b. System and software design

Penerapan sistem merupakan hal penting bagi pihak pengembang sistem informasi dalam menilai keberhasilan sistem informasi tersebut apakah berjalan sesuai perencanaan dan apakah telah memenuhi keinginan dari penggunanya (Purnomo, 2017)

Tahapan perancangan sistem mengalokasikan kebutuhan-kebutuhan sistem baik perangkat keras maupun perangkat lunak dengan membentuk arsitektur sistem secara keseluruhan. Perancangan perangkat lunak melibatkan identifikasi dan penggambaran abstraksi sistem dasar perangkat lunak dan hubungannya.

c. Implementation and unit testing

Pada tahap ini, perancangan perangkat lunak direalisasikan sebagai serangkaian program atau unit program. Pengujian melibatkan verifikasi bahwa setiap unit memenuhi spesifikasinya.

d. Integration and system testing

Unit-unit individu program atau program digabung dan diuji sebagai sebuah sistem lengkap untuk memastikan apakah sesuai dengan kebutuhan perangkat lunak atau tidak.

e. Operation and maintenance

Biasanya (walaupun tidak selalu), tahapan ini merupakan tahapan yang paling panjang. Sistem dipasang dan digunakan secara nyata. Maintenance melibatkan pembetulan kesalahan yang tidak ditemukan pada tahapan-tahapan sebelumnya, meningkatkan implementasi dari unit sistem, dan meningkatkan layanan sistem sebagai kebutuhan baru.

\section{Hasil dan Pembahasan}

\subsection{Tahapan Analisa}

World Wide Web atau yang dikenal juga dengan istilah web adalah suatu system yang berkaitan dengan dokumen digunakan sebagai media untuk menampilkan teks, gambar, multimedia dan lainnya pada jaringan internet (Yuniko \& Putra, 2019). Dengan adanya aplikasi pengabsenan berbasis website ini diharapkan dapat mengubah sistem yang semula manual menjadi lebih terkomputerisasi sehingga proses pencatatan serta akumulasi kehadiran dapat dilakukan secara otomatis dan lebih akurat. Hal ini dikarena perhitung jam masuk dan jam keluar dapat langsung terekam oleh sistem secara otomatis dan proses perhitungan pun dapat langsung terealisasi tanpa perlu bantuan hitung oleh user.

Setiap karyawan diwajibkan untuk mengikuti pengajian dengan perolehan 120 Menit di setiap bulannya. Hal ini dilakukan agar dapat meningkatkan disiplin setiap karyawan agar berperan aktif dalam kegiatan tersebut.

Adapun tahapan pengabsenan yang dimaksud adalah sebagai berikut :

1. Aktivitas Admin

a. Login

Berikut merupakan proses login yang dapat dilakukan oleh user maupun admin untuk masuk ke masing-masing halaman. Admin memiliki hak akses penuh dalam mengelola setiap fitur sementara user hanya dapat melihat rekapitulasi absensi pengajian secara perorangan saja. 


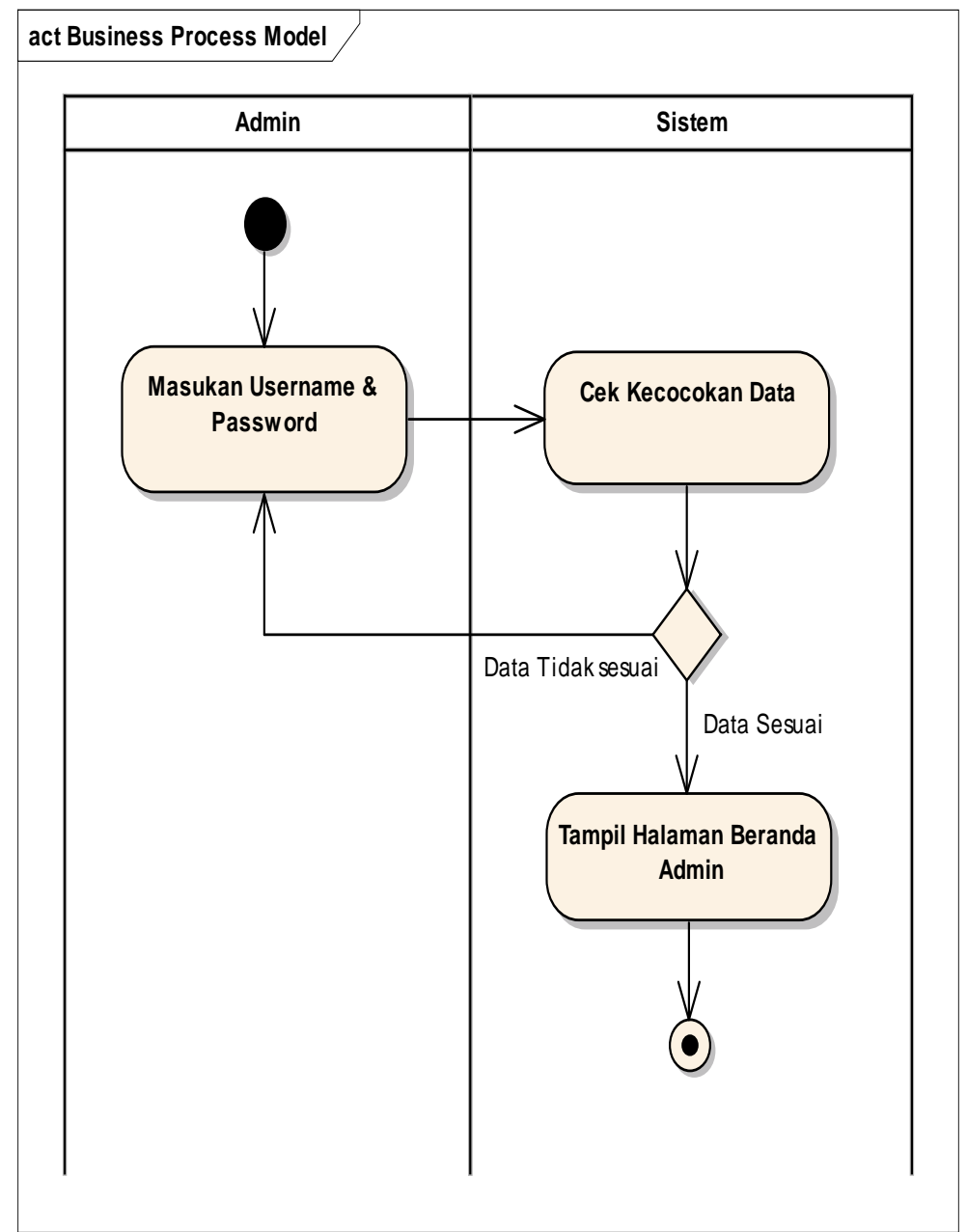

Gambar 1. Activity Diagram Login

b. Proses Absensi

Proses absesi hanya dilakukan oleh admin (petugas absensi). Absen dilakukan pada saat hari $H$ pengajian. Setiap karyawan yang masuk ke masjid akan langsung diinputkan absen dengan cara mencari nama karyawan yang bersangkutan lalu klik tombol simpan.

Perlu diketahui pada saat absensi dilakukan maka system akan secara otomatis merekam tanggal dan jam absensi dimulai. Diakhir sesi pengajian admin cukup mengklik tombol logout untuk mengakumulasi menit yang telah diperoleh oleh karyawan yang bersangkutan. Adapun minimal menit yang harus diperoleh minimal 120 menit atau 2 jam setara dengan dua kali melakukan pengajian setiap bulannya.

Logout lebih awal sebelum pengajian berakhir juga dapat dilakukan pada setiap karyawan yang izin mengakhiri pengajian di saat pengajian berlangsung karena suatu alasan tertentu dan system akan secara otomatis merekam waktu terakhir pengajian dan menit pun akan terakumulasi secara otomatis. Apabila terdapat karyawan yang tidak memenuhi ketentuan pengajian yakni tidak melebihi durasi waktu yang telah ditentukan maka karyawan tersebut akan dikenakan sanksi. 


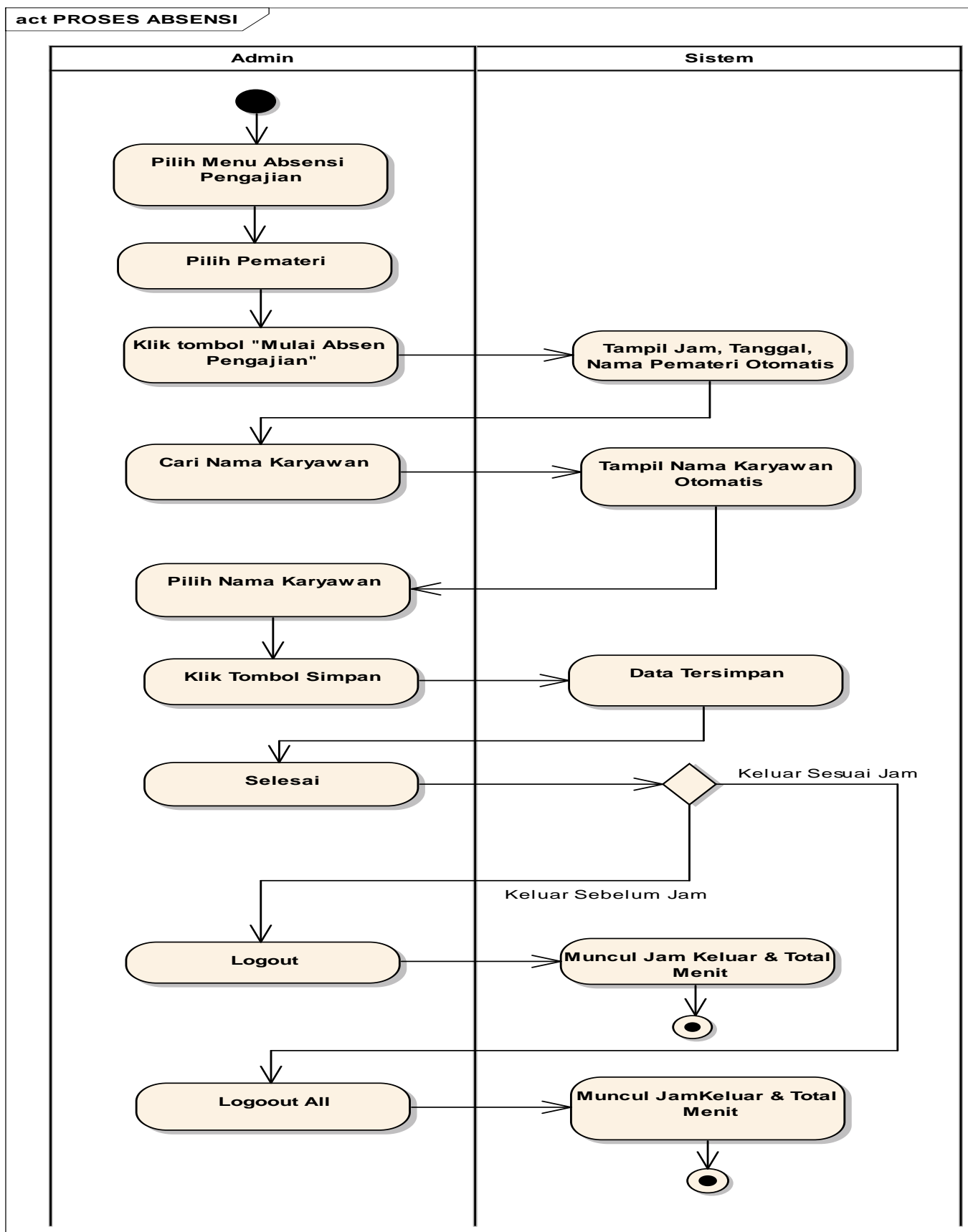

Gambar 2. Activity Diagram Absensi 
c. Export Excel

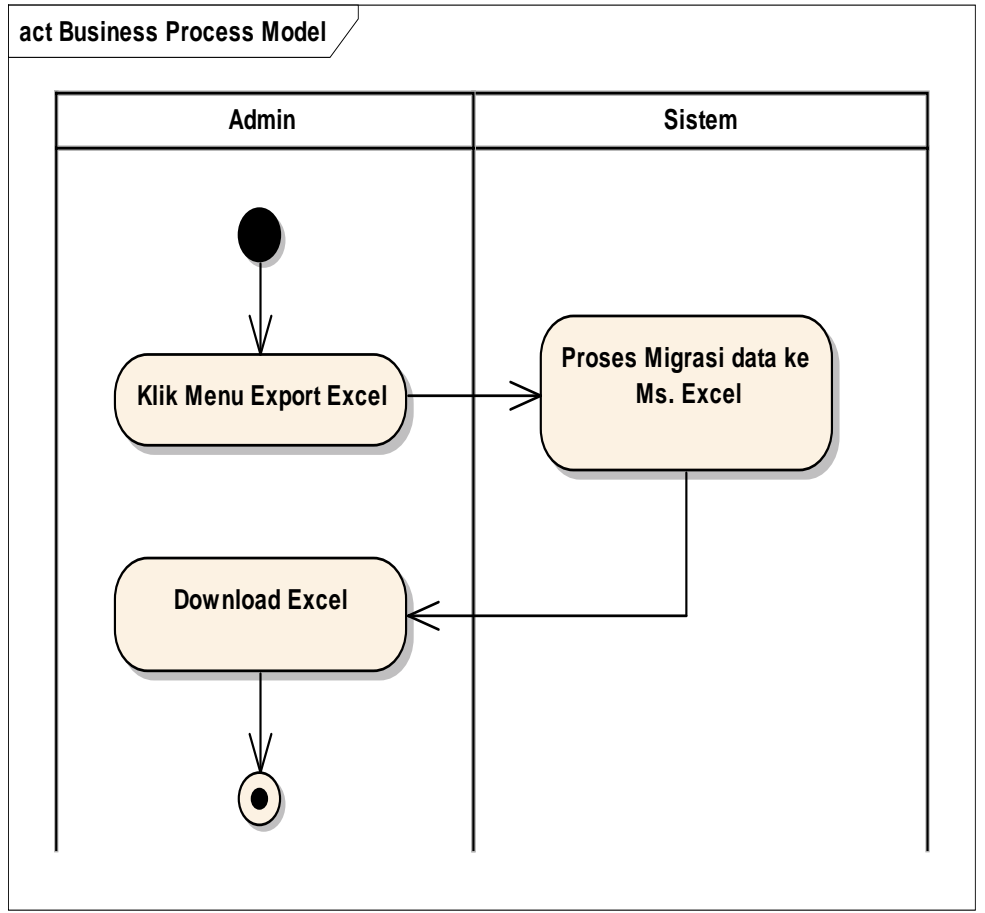

Gambar 3. Activity Diagram Export Excel

Admin juga dapat mengeksport data absensi pengajian yang sebelum telah diinput dengan kategori waktu tertentu.

2. Aktivitas Karyawan

a. Melihat status absensi pengajian
Karyawan dapat melihat status absensi pengajiannya pada halaman website masing-masing. Informasi yang ditampilkan berupa identitas diri, tanggal, jam pengajian beserta perolehan akumuilasi menit selama satu bulan.

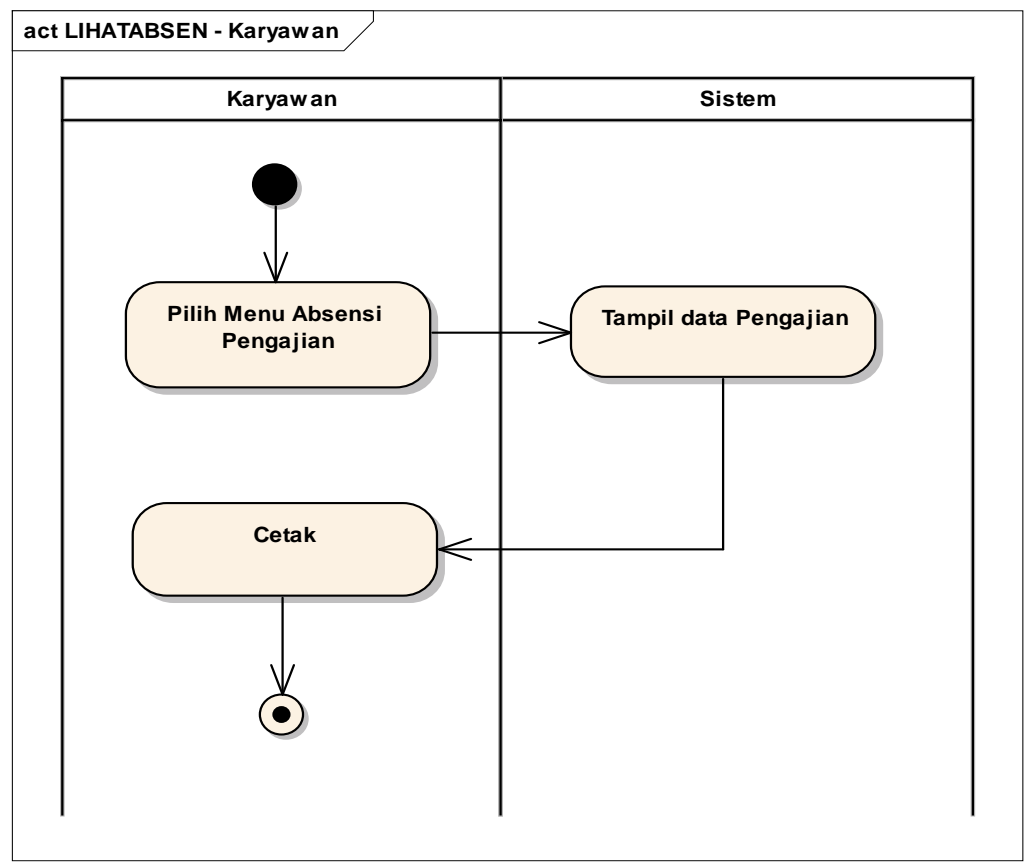

Gambar 4.

Activity Diagram status pengajian 


\subsection{Halaman antarmuka aplikasi}

\section{a. Halaman login}

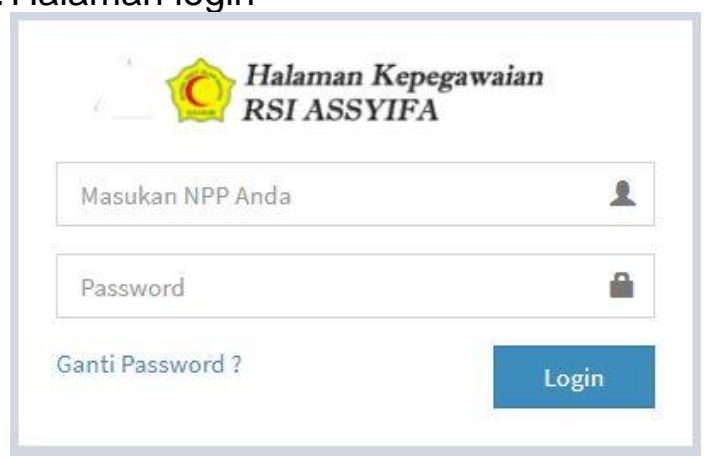

Gambar 5. Halaman Login

Sumber : RSI ASSYIFA Sukabumi (2020)

b. Halaman pilih pemateri

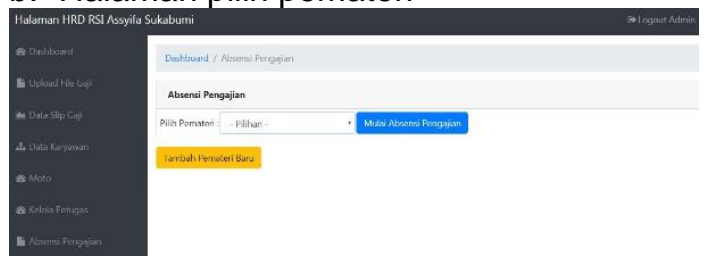

Gambar 6. Halaman Pemateri Sumber : RSI ASSYIFA Sukabumi (2020)

c. Halaman Absensi

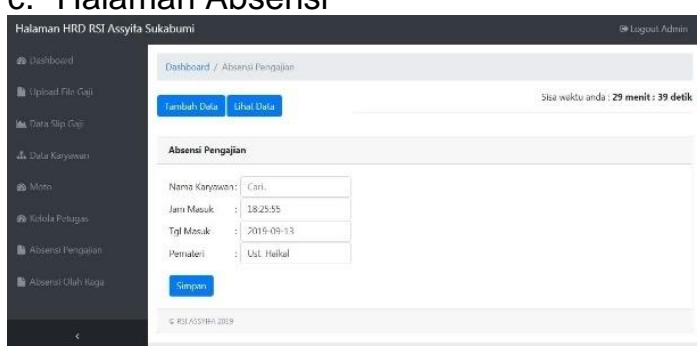

Gambar 7. Halaman Absensi

Sumber : RSI ASSYIFA Sukabumi (2020)

d. Halaman hasil absen

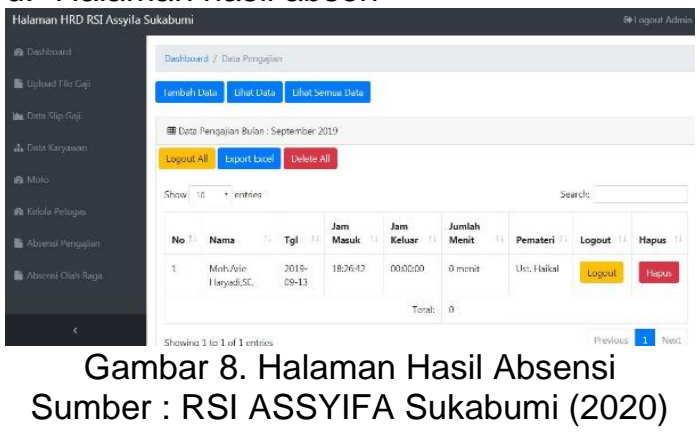

e. Halaman lihat status absen karyawan

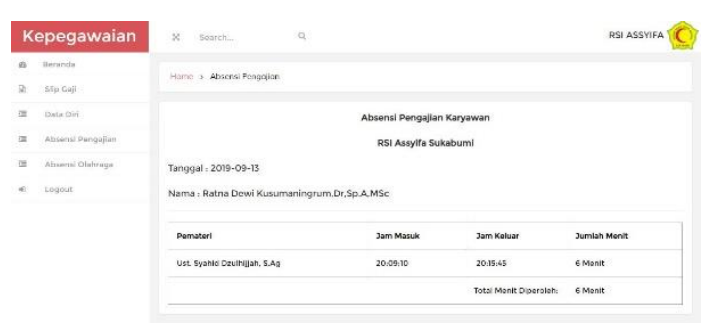

Gambar 9. Halaman lihat status absen Sumber : RSI ASSYIFA Sukabumi (2020)

\section{Kesimpulan}

Berdasarkan penelitian yang telah dilakukan pada sistem absensi pengajian online berbasis web maupun mobile web maka dapat diambil kesimpulan sebagai berikut :

a. Dengan adanya sistem absensi pengajian berbasis online tentunya dapat diakses dimanapun dan dengan perangkat apapun sehingga dapat mengurangi penggunaan kertas

b. Proses pencatatan serta akumulasi absen masuk dan keluar dapat lebih tepat dan akurat mengingat sistem akan otomatis membaca tanggal dan jam saat aplikasi tersebut digunakan oleh admin sehingga dapat meminimaliri human error

c. Disamping itu, karyawan dapat melihat status absensi mereka masing-masing serta akumulasi menit yang telah diperoleh. Hal ini tentunya dapat dapat memotivasi karyawan serta menanmkan rasa disiplin terutama dalam hal kegiatan pengajian rutin

\section{Referensi}

Kurniawan, A., \& Oki Rosanto, M. R. S. (2018). Pengaruh Kualitas Pelayanan Terhadap Kepuasan Pasien Bpjs Pada Rsud Budhi Asih Jakarta Timur. AtTadbir: Jurnal Ilmiah Manajemen, 2(1), 1-10.

https://doi.org/10.31602/atd.v2i1.1191

Basarah, R. S. (2017, 03 27). Khazanah : MUKISI Siapkan Sertifikasi Rumah Sakit Syariah. Retrieved Agustus 09, 2020, from Republika: https://www.republika.co.id/berita/du nia-islam/islamnusantara/17/03/27/ongy $1 \times 352-$ mukisi-siapkan-sertifikasi-rumahsakit-syariah

Dipang, L. (2013). Pengembangan Sumber Daya Manusia dalam Peningkatan 
Kinerja Karyawan pada PT. Hasjrat

Abadi Manado. Emba, 1(3), 10801088.

https://doi.org/10.1017/CBO978110741 5324.004

European Environment Agency (EEA). (2019). 済無No Title No Title. 53(9), 1689-1699.

https://doi.org/10.1017/СВO978110741 5324.004

Purnomo, D. (2017). Model Prototyping Pada Pengembangan Sistem Informasi. J I M P - Jurnal Informatika Merdeka Pasuruan, 2(2), 54-61. https://doi.org/10.37438/jimp.v2i2.67

Rahardja, U., Sholeh, O., \& Nursetianingsih, F. (2015). Penggunaan dashboard untuk mengontrol kinerja profesionalisme pegawai pada $\mathrm{Pt}$. Sinarmas Land Property. Jurnal Teknologii Informasi Dan Multimedia, 1(2), 415-418.

Rahman, A. (2019). Modernisasi Teknologi Kereta Api Di Sumatera Barat Masa Hindia Belanda (1871-1933). Siddhayatra: Jurnal Arkeologi, 24(1), 17. https://doi.org/10.24832/siddhayatra.v2 $4 \mathrm{i} 1.146$

Sasmito, G. W. (2017). Penerapan Metode Waterfall Pada Desain Sistem Informasi Geografis Industri Kabupaten Tegal. Jurnal Informatika:Jurnal Pengembangan IT (JPIT), 2(1), 6-12.

Yuniko, F. T., \& Putra, F. K. (2019). Penerapan Teknologi Informasi Web Programing Untuk Meningkatkan Pelayanan Publik Dalam Bidang Kebijakan Administrasi Kependudukan. JOISIE (Journal Of Information Systems And Informatics Engineering), 1(1),

https://doi.org/10.35145/joisie.v1i1.387

Zulfah, S. (2018). Pengaruh Perkembangan Teknologi Informasi Lingkungan (Studi Kasus Kelurahan Siti Rejo I Medan). Buletin Utama Teknik, 13(2), 143-149. https://jurnal.uisu.ac.id/index.php/but/ar ticle/view/284 